\title{
Cytological variants (CytV) of papillary thyroid carcinoma: clinical presentations according with the presence of BRAF mutation
}

Amelia Oleaga, Eider Etxeberría, Laura Calles, Fernando Goñi, Maite Pérez de Ciriza, Elena Fuertes, Aitziber Ugalde, Miguel Paja. Endocrinology Department ${ }^{1}$, Pathology Department ${ }^{2}$.

Universitary Basurto Hospital. Bilbao. Spain.

EP 898

\section{Introduction:}

BRAF(V600E) mutation has received great attention to improve risk stratification in patients with papillary thyroid carcinoma (PTC). Its prognostic value in the different CytV of PTC is not well established. The aim of this study was to investigate differences in clinicopathological features according to CytV, among patients harbouring the mutation.

\section{Description of methods/Design:}

We evaluated 102 patients with pathological diagnosis of PTC. All of them underwent total thyroidectomy and radioiodine ablation, 87 central lymph node (LN) dissection (67 prophylactic), and 18 lateral neck dissection as well. DNA was extracted from neoplastic cells and BRAF mutation was detected by PCR and sequencing. Analysis included histological subtype, age, multifocality (MF), extrathyroidal extension (EET), LN metastases (LNMx), LN ratio (LNR) (number of positive LN divided by the total amount of dissected nodes) and clinical remission (CR) after 1 year of initial treatment (stimulated thyroglobulin $(\mathrm{Tg})$ undetectable, no presence of $\mathrm{Tg}$ antibodies and negative cervical ultrasound).

Results:
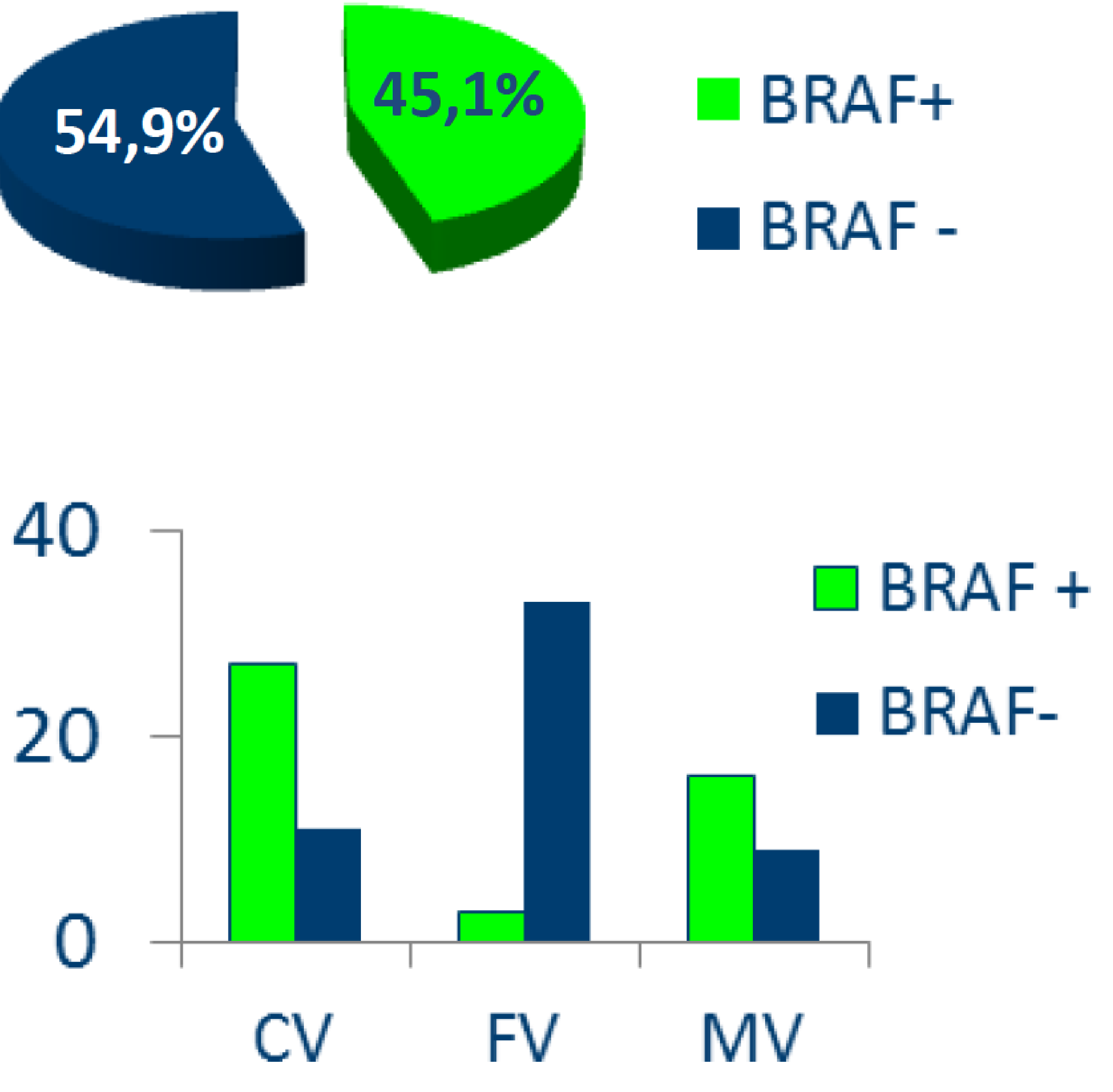

\begin{tabular}{|l|c|c|c|c|c|c|}
\hline & \multicolumn{2}{|c|}{$\begin{array}{c}\text { Classic variant } \\
\text { (CV) }\end{array}$} & \multicolumn{2}{|c|}{$\begin{array}{c}\text { Follicular variant } \\
\text { (FV) }\end{array}$} & \multicolumn{2}{|c|}{$\begin{array}{c}\text { Mixed forms } \\
\text { (MV) }\end{array}$} \\
\hline BRAF & + & - & + & - & + & - \\
\hline N & $27(71 \%)$ & 11 & $3(9 \%)$ & 33 & $16(64 \%)$ & 9 \\
\hline Mean & & & & & & \\
\hline Age & 47 & 52,4 & 58 & 52,4 & 60 & 47,7 \\
\hline (years) & & & & & & \\
\hline MF \% & 59 & 81 & 9 & 36 & 50 & 55 \\
\hline EET \% & 51 & 45 & 33 & 9,1 & 33 & 44 \\
\hline LNMx\% & 85 & 54,5 & 0 & 9,1 & 33 & 66 \\
\hline LNR \% & 22,4 & 10 & 0 & 2,2 & 6,1 & 6,2 \\
\hline CR & $15 / 20$ & $8 / 10$ & $1 / 1$ & $12 / 13$ & $11 / 11$ & $4 / 6$ \\
\hline
\end{tabular}

\section{Conclusions}

In our series BRAF mutation is more prevalent in CV of PTC as it has been described previously, and at a younger age.

We emphasize the high prevalence of LNMx and the higher LNR found in patients with CV tumors. Given the prognostic value of BRAF mutation, these results confirm the more benign behaviour of FVPTC. 